\title{
Head and neck cancer in South Asia: macroeconomic consequences and the role of the head and neck surgeon
}

Blake C. Alkire, $\mathrm{MD}^{1,2,3}$; Regan W. Bergmark, $\mathrm{MD}^{1,3}$; Kyle Chambers, $\mathrm{MD}^{1,3}$; Derrick T. Lin, $\mathrm{MD}^{3,5}$; Daniel G. Deschler, MD ${ }^{3,5}$; Mack L. Cheney, MD ${ }^{1,2,3}$; John G. Meara, MD ${ }^{2,4}$

${ }^{1}$ Office of Global Surgery, Massachusetts Eye and Ear Infirmary, 243 Charles Street, Boston MA, 02114, USA

${ }^{2}$ Program in Global Surgery and Social Change, Department of Global Health and Social Medicine, Harvard Medical School, Boston MA, USA

${ }^{3}$ Department of Otology and Laryngology, Harvard Medical School, Boston MA, USA

${ }^{4}$ Department of Plastic and Oral Surgery, Boston Children's Hospital, 300 Longwood Avenue, Boston MA, 02115, USA

${ }^{5}$ Division of Head and Neck Surgery, Massachusetts Eye and Ear Infirmary, 243 Charles Street, Boston MA, 02114,USA

C

Funding: None.

The results of this study were presented as a poster at the launch of the Lancet Commission on

Global Surgery in April, 2015 and accepted as an abstract in The Lancet.

\section{Corresponding Author:}

Blake Alkire

Department of Otolaryngology, Massachusetts Eye and Ear Infirmary

243 Charles St, Boston, MA 02114

blakealkire@gmail.com

903-244-7326

Running title: Macroeconomic consequences of head neck cancer in South Asia

Keywords: economic burden, head and neck cancer, global surgery, South Asia, economic analysis

This is the author manuscript accepted for publication and has undergone full peer review but has not been through the copyediting, typesetting, pagination and proofreading process, which may lead to differences between this version and the Version record. Please cite this article as doi:10.1002/ hed.24430. 


\section{Abstract}

\section{Background}

Head and neck cancer comprises a substantial portion of the burden of disease in South Asia, and there is an undersupply of surgical capacity in this region. We aimed to estimate the economic welfare losses due to head and neck cancer in India, Pakistan, and Bangladesh in 2010.

\section{Methods}

We used publicly available estimates of head and neck cancer morbidity and mortality along with a concept termed the value of a statistical life to estimate economic welfare losses in the aforementioned countries in 2010.

\section{Results}

Economic losses due to head and neck cancer in India, Pakistan, and Bangladesh totaled \$16.9 billion (2010 USD), equivalent to $0.26 \%$ of the region's economic output. Bangladesh, the poorest country, experienced the greatest proportional losses.

\section{Conclusions}

The economic consequences of head and neck cancer in South Asia are significant, and building surgical capacity is essential to begin to address this burden. 


\section{Introduction}

In 2000, the United Nations established the Millennium Development Goals (MDGs), a set of eight development goals directed at reducing extreme poverty by 2015 . Three of the eight goals were health-related, and each outlined specific targets that could be quantitatively assessed. The debate over the legacy of the MDGs has only just begun, but it is clear that progress was made in many countries to reduce poverty rates, childhood and maternal mortality, and increase access to essential medicines. ${ }^{1}$ As the MDG deadline has now arrived, there is a renewed interest in defining a global health agenda, including the recent adoption of the Sustainable Development Goals. Much of this focus has been on chronic diseases, or non-communicable diseases, which includes oncologic disease. ${ }^{2,3}$ Surgery, as part of multimodality cancer care and also more broadly, is also receiving increased levels of attention by the global health community, evidenced by The Lancet's Commission on Global Surgery and dedication of an entire volume of the third edition of Disease Control Priorities, the definitive text on cost-effective interventions in low-and-middle income countries, to essential surgery. ${ }^{4,5}$ As advocacy for surgery as an integral part of universal health care has become more prominent, the stark reality of the complete lack of access to surgery in much of the world also been made clear: more than five billion worldwide do not have access to safe, affordable surgical care. ${ }^{6}$

As evidence continues to point to a significant unmet need for surgical and broader oncologic services in low- and middle-income countries, ${ }^{5,7}$ it has become clear that head and neck surgery has an essential role in closing the gap. Head and neck cancers (HNC) represent a range of diverse pathologies, although the vast majority are squamous cell carcinomas that affect the oral cavity, oropharynx, hypopharynx, and larynx. With 680,000 new cases each year, head and neck cancer (excluding thyroid cancer) is the sixth most commonly diagnosed cancer and contributes 
to a substantial portion of global mortality: up to 375,000 deaths are attributable to HNC each year. ${ }^{8}$ Additionally, as the prevalence of infectious diseases declines and rates of chronic disease in developing countries rise (the so-called "epidemiological transition"), the incidence of head and neck cancer is only expected to increase. ${ }^{7,9}$ Low and middle-income countries in South Asia are noted to be particularly affected by HNC, as India, Pakistan, and Bangladesh contribute to more than $35 \%$ of all HNC mortality, but only $22 \%$ of the global population. ${ }^{10,11}$ Although multimodality treatments including radiation therapy, chemotherapy and surgery are the standard of care for advanced disease, excellent cure rates are achievable for early stage disease using surgery as a single modality. Furthermore, given that one procedure can result in cure, surgery has the potential to be a particularly cost-effective and accessible treatment option in a lowresource setting when compared to radiation therapy and chemotherapy, the latter of which is not curative as a single modality agent. However, while in general surgical interventions can be as cost-effective as other public health interventions including anti-retroviral medication for $\mathrm{HIV}{ }^{12}$ detailed studies regarding cancer surgery cost-effectiveness is lacking in low- and middleincome countries. ${ }^{13}$

While burden of disease estimates are essential for the practice of global health, economic analyses allow for understanding the impact of disease processes on a population, informing resource allocation, and guiding policy. ${ }^{14,15}$ There is presently a lack of published data on the macroeconomic impact of head and neck cancer within communities in low- and middle-income countries (LMICs). To better understand the potential impact of adequate access to treatment for head and neck cancer, we sought to quantify the economic burden of head and neck cancer. Given the considerable burden of head and neck cancer in South Asia, ${ }^{15}$ we hypothesized that the estimated economic welfare losses would be equivalent to a significant portion of the region's 
total economic output. We use a concept known as the value of a statistical life to quantify the economic burden of HNC in three countries: India, Pakistan, and Bangladesh.

\section{Materials and Methods}

\section{Measuring and Valuing Health - A Brief Introduction<smiles>C1CC1</smiles>

The Disability-Adjusted Life-Year (DALY) is a health metric that is used as the primary measure by which the global burden of disease is estimated. The DALY attempts to capture both

premature mortality, measured in years of life lost (YLLs), and morbidity, measured in years lost to disability (YLDs), secondary to a disease. One DALY is equal to one year of healthy life lost, and thus it is desirable to decrease DALYs in a population. Total DALYs secondary to a disease process are found by adding YLDs and YLLs. ${ }^{16}$

The value of a statistical life (VSL) is a concept that has been developed by economists over the past 40 years and is derived from studies that assess the monetary value individuals place on changes in their risk of mortality. ${ }^{17}$ The VSL is the maximum amount an individual would be willing to pay to avert their risk of death. As an example, an individual who accepts $\$ 2,000$ in decreased wages to switch to an occupation where the fatality risk is 0.001 lower than their current occupation is implicitly revealing that she values her risk reduction at $\$ 2$ million (= $\$ 2,000 / 0 \cdot 001)$. In this example, the VSL is $\$ 2$ million. Comparing the wages of occupations with different risk profiles is one approach economists have developed to estimate VSL, and is generally considered to be more robust than the competing survey-based approaches. ${ }^{18,19}$ 
Formal VSL studies have been performed in few developing countries, but methods have been devised for estimating the VSL in a country in which empirical studies have not been performed. ${ }^{18}$ Transferring VSL estimates to low- and middle income countries is common practice in the economics literature. ${ }^{20}$ Using the ratio of gross domestic product per capita (GDP/capita) as a conversion factor, one can transfer VSL estimates from a country in which empirical studies have been performed to countries in which they have not. Central to this transfer method is a parameter known as the "income elasticity of VSL" (IE-VSL), which dictates how VSL changes in proportion to the relative income of the two considered countries. Increasing the IE-VSL results in decreased VSL estimates in LMICs when transferring from high-income countries. Although IE-VSL's of 0.5-1.0 are traditionally used when transferring estimates from high-income countries to LMICs, recent evidence suggests that an IE-VSL of 1.5 may be more appropriate for low-income countries. ${ }^{20}$ This study uses an IE-VSL value of 1.5 as the headline result, with a sensitivity analysis of 0.55 and 1.0 .

To use VSL to place an economic value on a DALY, it must be converted to its annualized equivalent, the value of a statistical life-year (VSLY). Assumptions regarding VSLY and how it varies with age, region-specific income, and region-specific life-expectancy are incorporated into the model (see appendix). To estimate the total economic welfare losses of a disease, one multiplies the VSLY by DALYs. The counterfactual in this analysis is absence of disease; therefore, the estimated losses are gross estimates, and do not imply potential benefit of treatment, nor do they account for potential treatment cost. This is consistent with prior analyses that employ similar methodologies and scope. ${ }^{21,22}$

The VSLY has also been used to value DALYs in the Copenhagen Consensus series ${ }^{23}$ and to assess the macroeconomic burden of non-communicable diseases and cancer. ${ }^{21,22}$ Further, the 
recent Lancet Global Health 2035 commission and Lancet Commission on Global Surgery employed a VSL methodology for estimating the macroeconomic value of changes in mortality in LMICs. ${ }^{14,24}$

Monetary estimates are expressed in 2010 United States dollars (USD), adjusted for purchasing power parity (PPP) (see appendix for details). We also present welfare losses in terms of their equivalent percentage of 2010 GDP; it is important to note that these do not represent actual losses in GDP, but are expressed relative to GDP to provide a sense of scale.

\section{Study Population}

This study relies on head and neck cancer mortality and morbidity estimates from the Institute of Health Metrics' (IHME) 2010 global burden of disease (GBD) study. ${ }^{11,25} \mathrm{HNC}$ is broken down into the following categories in GBD 2010: "mouth cancer[sic]," "cancer of the oropharynx and other pharynx," "larynx cancer," "nasopharynx cancer," and "thyroid cancer." We re-term "mouth cancer" as oral cavity cancer. The age-specific total number of deaths for each of these cancers in India, Pakistan, and Bangladesh were included; we used these deaths to calculate total discounted YLLs within the context of each countries age-specific life-expectancy. We also used age-specific YLD estimates for each country from GBD to capture morbidity. Given the number of age-specific deaths and total YLDs in each country for each cancer, we estimate the number of DALYs due to HNC, and using the described methods above, derive economic welfare losses from these estimates. Table one gives the number of deaths by country and cancer site of origin.

Statistical analysis was performed in Excel 2010 (Microsoft Corporation -- Redmond, Washington, USA). 


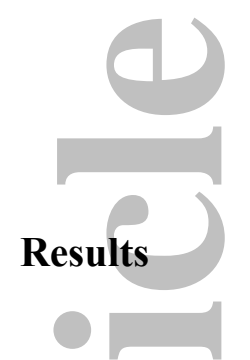

In 2010, the most conservative estimate of the total economic welfare losses due to head and neck cancer in India, Pakistan, and Bangladesh is \$16.9 billion (2010 USD, PPP), equivalent to $0.26 \%$ of their combined gross domestic product (Table 2 , Figure 1 ). When adjusted for the size of their respective economies, Bangladesh, the poorest of the three countries, had the greatest loss, estimated to be equivalent to $0.29 \%$ of its 2010 economic output. When less restrictive assumptions of VSL are applied, losses increase to $\$ 57$ billion (2010 USD, PPP), or $0.87 \%$ of combined GDP (appendix table 1). Oropharyngeal and hypopharyngeal cancer made up the largest share of the total burden at 39\%, followed closely by oral cavity cancer at $34 \%$.

\section{Discussion}

Based on the mortality and morbidity estimates of the Global Burden of Disease 2010 Study, ${ }^{11}$ we estimate the total economic welfare losses of head and neck cancer (HNC) in three countries in South Asia: India, Pakistan, and Bangladesh (IPB). Using the most conservative valuation of morbidity and mortality, we find that HNC resulted in an economic welfare losses of $\$ 16.9$ billion, equivalent to $0.26 \%$ of their combined gross domestic product. These results suggest that in addition to the suffering inflicted by HNC mortality and morbidity, there are significant economic welfare losses. 
While the disease burden of HNC in South Asia has been well-documented, ${ }^{8}$ this is the first estimate of the macroeconomic impact of HNC in a country or region of which we are aware. Mahal et. al. examined the effect of all cancer on household expenditure in India. Given the undersupply of public financing in India, ${ }^{26}$ it is not surprising that when compared to families without cancer, Mahal found that households caring for a family member with cancer experienced higher rates of borrowing, liquidation of assets, and overall health expenditure. ${ }^{27}$ While Mahal's study examines the microeconomic impact of cancer on household expenditure, our results estimate economic losses from a societal, or macroeconomic perspective. Therefore, while our results are not comparable, they are complementary in that they both suggest that cancer inflicts a substantial economic burden on the region.

The available evidence suggests that much of the mortality incurred in these countries is unnecessary. One method to compare disease burden across regions that, while crude, can begin to place an estimate on unnecessary mortality is to compute a mortality to incidence ratio. Using age-standardized incidence and mortality rates, ${ }^{9}$ mortality to incidence ratios for oral cavity, oropharygeal, hypopharyngeal, and laryngeal cancer in IPB is 0.72 , while only 0.31 in highly developed nations. Other studies have estimated 5-year survival for oral cavity and laryngeal cancer in India and Pakistan and show consistent deficits when compared to 5-year survival in other parts of the world. ${ }^{28}$

A number of strategies are available for combating head and neck cancer. Two recent Lancet series have highlighted the burden of cancer in India and proposed solutions to address the crisis, and we highlight those specific to HNC. ${ }^{2,26,29}$ A significant number of deaths could be prevented by addressing the relatively greater incidence of HNC in South Asia. Primary prevention begins with addressing tobacco and alcohol abuse. Educational initiatives have been shown to be 
effective in India at reducing tobacco use, ${ }^{30}$ but heavy taxation of tobacco products has been repeatedly shown to be the best opportunity to combat not only HNC, but non-communicable disease in general. ${ }^{14}$ HPV vaccine could play a role in addressing oropharyngeal cancer rates ${ }^{31}$ if subset analyses reveals that a significant proportion of oropharyngeal cancers are HPV related as they are in the US and other developed nations. Recent data suggest that HPV plays a role in oropharyngeal cancer in this region, albeit less than the United States. ${ }^{32}$ Additional strategies can be aimed at earlier detection of HNC, so that malignancy is detected while in more indolent stages. Sankaranarayanan et. al. performed a cluster randomized control trial in India that compared overall mortality between patients undergoing oral cavity screening for cancer with controls that did not undergo screening and found that screening high-risk patients for oral cavity cancer resulted in a statistically significant reduction in mortality. ${ }^{33}$ Other studies, however, have not identified a mortality benefit. ${ }^{34}$

While strategies aimed at primary and secondary prevention will be crucial in addressing HNC, there will continue to be a central role for cancer treatment, which requires surgical interventions that are both diagnostic and curative. The mortality to incidence ratios noted above are unlikely to be explained by inadequate preventive measures alone, especially as they are adjusted to incidence rates and therefore suggest that even if incidence rates decline, there will still be work to do to close the gap between high-income countries and South Asia. Indeed, surgery is the cornerstone of treatment for oral cavity cancer, and yet there are only 200 head and neck surgeons in all of India, a country with 1.2 billion people. ${ }^{35}$ Comprehensive cancer centers, such as the Tata Memorial Hospital in Mumbai, are available, but exist almost exclusively in major urban centers; rural populations, often the most poor, are often unable to access meaningful care. Basic pathology services are not available in many parts of India. ${ }^{35}$ While the feasibility of 
delivering highly complex care at a reasonable cost remains a concern, there is evidence that HNC patients in rural South Asia can in fact receive comprehensive care (including free flap reconstruction) at a relatively affordable cost. ${ }^{36}$

Importantly, we are not arguing that training head and neck surgeons in isolation is a panacea. While recent data underscore the significant undersupply of the surgical workforce in India, Pakistan, and Bangladesh, ${ }^{37}$ improving access to surgical care and cancer care requires addressing a number of potential barriers. The Lancet Commission on Global Surgery has made over 100 policy recommendations, including improving financing mechanisms so that patients do not experience financial catastrophe in paying for care, methods for addressing transportation and hospital infrastructure gaps, and approaches to improve distribution of the surgical workforce, to name a only a few. ${ }^{38}$ We would argue that these complexities should be addressed in parallel with addressing the surgical workforce. Ultimately, cancer care is best provided in the context of a resilient health system, of which providers form a crucial component.

Head and neck surgeons at every country income level are uniquely qualified to address a number of specific reforms, and below we highlight their potential role in improving surgical capacity, research, and advocacy for public health measures.

Training and Retention of Surgeons: Training partnerships and "twinning" models pairing academic institutions in developed and developing regions are promising ways to grow the surgical workforce. In this model, attending head and neck surgeons mentor trainees or certified surgeons where training opportunities are limited. ${ }^{39}$ Others have advocated for bursts of training in the form of surgical "camps," specialist outreach from urban centers to rural districts, and 
investment by Ministries of Health in health infrastructure and human resources to improve training and retention of staff. ${ }^{40}$

Research: Research goals include: (A) understanding surgical disease, surgical capacity, and safety and (B) expanding research capacity and indigenous academic surgeons. This may be facilitated by (C) encouraging global head and neck surgery research and work from high income countries.

(A) There should be coordinated efforts to evaluate head and neck cancer incidence, establish and evaluate best practices and effectiveness of prevention, and early detection and surgical treatment of head and neck cancer. In practice, this may look like establishing basic surgical outcomes measures for hospitals or regions, developing more robust cancer registries, and conducting epidemiological studies evaluating cancer incidence and access to care. Partnerships between academic institutions in South Asia with those in developed centers can help to develop research capacity to better understand head and neck cancer incidence, presentation, and surgical outcomes. Surgical outcomes and capacity can be evaluated successfully through basic interventions even in very poor settings, as has been shown by the WHO Safe Surgery Saves Lives Measurement and Study Groups and others. Basic research in head and neck cancer in South Asia is at an early stage and will require investment and training. ${ }^{41}$

(B) Head and neck surgeons should prioritize development of research infrastructure with academic surgeons in South Asia. Improving research capacity could be facilitated by collaboration with high-income countries, including help with grant writing, methodology, data analysis and publishing. ${ }^{41}$

(C) In high-income countries, academic centers should support and foster research in global 
surgery. Providing tenure track opportunities for surgeons focusing on global health has been advocated for surgery more broadly. ${ }^{42}$

Public Health Advocacy: Advocating for the establishment of better access to surgical care may help bring attention to the burden of surgical disease and need for human resources, research and infrastructure development. In addition, there are looming public health concerns such as tobacco use, ${ }^{43}$ the spread of which leads to a significant increases in head and neck cancer. Head and neck surgeons should be at the forefront of international policy efforts to limit the spread of tobacco use and assist tobacco product cessation, as well as support efforts for vaccination against human papilloma virus, which disproportionately affects people in LMICs and is a significant risk factor for oropharyngeal cancer. ${ }^{44}$
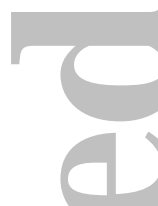

\section{Limitations}

This study has a number of limitations. The relatively small number of formal VSL studies in developing countries limits the certainty of our estimates. Fortunately, there have been VSL studies in India, ${ }^{45}$ and those estimates are closely aligned with the upper-bound of our VSL estimates. Nonetheless, we report our most conservative estimate so as not to overstate these values. Some have criticized VSL for attempting to place a monetary value on life. We assert that VSL is not valuing life, which has infinite value, but that VSL attempts to capture how society values reductions in risk of mortality. The DALY, a well-described and accepted method upon which we based our estimates, does have potential methodological imperfections thoroughly discussed elsewhere. ${ }^{46}$ In addition, this study cannot be used in isolation for prioritysetting, as we have only described the magnitude of the problem. While macroeconomic studies 
such as these have proven useful to ministries of finance and donors, ${ }^{47}$ data regarding costeffectiveness is also needed. Finally, the epidemiological estimates we relied upon are in part the result of modelling, which further limits the certainty of our estimates. As an example, the divergence in the relative burden of oral cavity cancer -- estimated by IHME to account for only $8 \%$ of head and neck cancer deaths in Bangladesh and up to $28 \%$ and $33 \%$ of deaths in Pakistan and India, respectively - differs from another often cited estimate of the global burden of cancer, which reveals a more consistent burden of oral cavity cancer among the three countries. ${ }^{8}$ The GLOBOCAN 2012 study estimates that oral cavity cancer comprises $36 \%$, 48\%, and 55\% of head and neck cancer deaths in Bangledesh, India, and Pakistan respectively. These differences further underscore the extent of modeling in burden of disease estimates and consequently limit the certainty of our results.

\section{Conclusions}

Head and neck cancer is responsible for a significant proportion of the total burden of disease in South Asia. Consistent with this, we demonstrate that in 2010, HNC was responsible for a staggering \$16.9 billion loss in economic welfare in India, Pakistan, and Bangladesh. Estimates of mortality and incidence suggest that when compared to high-performing countries, the number of lives lost could be substantially reduced and the current degree of suffering and welfare loss is unnecessary. While prevention and public health measures are central to combatting HNC, surgery is necessary for diagnosis and is the standard of care for unimodality treatment for early stage oral cancer and must play a role if we are to address the burden of HNC within the broader context of a strong health system. Head and neck surgeons have a crucial role to play by supporting research, advocacy, training, and collaboration with local stakeholders in the development of local surgical capacity. 


\begin{abstract}
Author Contributions: BCA and JGM conceived of the project. BCA performed initial data collection and analysis with input from JGM, MLC, RB, and KC. BCA and RB wrote the first draft of the paper with subsequent revision by JGM, MLC, DD, DL, and KC. All authors approved of submission.
\end{abstract}
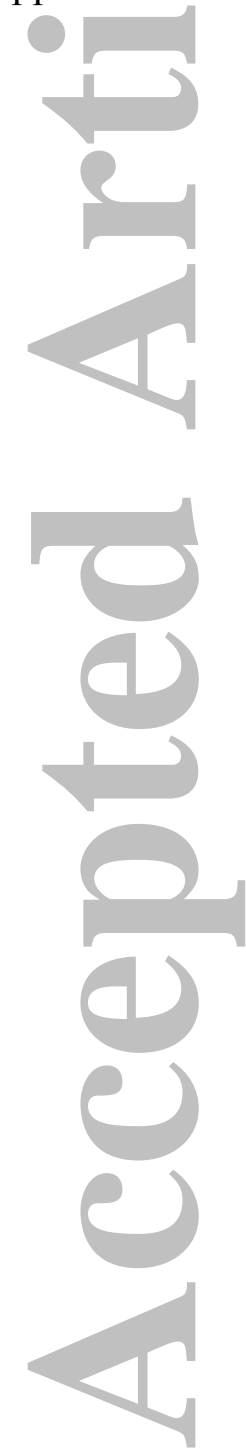

John Wiley \& Sons, Inc. 


\section{Tables}

\begin{tabular}{|c|c|c|c|c|}
\hline \multicolumn{4}{|c|}{ Country } & \multirow[b]{2}{*}{ Total } \\
\hline Site of Origin & Bangladesh & India & Pakistan & \\
\hline Larynx & 6512 & 20267 & 4106 & 30885 \\
\hline Nasopharynx & 260 & 3791 & 630 & 4681 \\
\hline Oral cavity & 1534 & 32063 & 4797 & 38393 \\
\hline $\begin{array}{r}\text { Oropharynx and } \\
\text { Hypopharynx }\end{array}$ & 11478 & 38942 & 4353 & 54772 \\
\hline Thyroid & 328 & 3742 & 591 & 4661 \\
\hline Total & 20112 & 98804 & 14477 & 133392 \\
\hline
\end{tabular}

Table 2: Economic welfare losses (millions, 2010 USD, PPP) by country and cancer site of origin using baseline value of a statistical life (VSL) assumptions ${ }^{\text {a }}$ (equivalent percentage of gross domestic product)

\begin{tabular}{|c|c|c|c|c|}
\hline & & Country & & \\
\hline Site of Origin & Bangladesh & India & Pakistan & Total \\
\hline Larynx & $\$ 303(0.10 \%)$ & $\$ 2,610(0.05 \%)$ & $\$ 489$ (0.07\%) & $\$ 3,403(0.05 \%)$ \\
\hline Nasopharynx & $\$ 12(0.004 \%)$ & $\$ 571(0.01 \%)$ & $\$ 88(0.01 \%)$ & $\$ 670$ (0.01\%) \\
\hline Oral cavity & $\$ 67(0.02 \%)$ & $\$ 4,938(0.09 \%)$ & $\$ 666$ (0.09\%) & $\$ 5,670(0.09 \%)$ \\
\hline $\begin{array}{l}\text { Oropharynx and } \\
\text { Hypopharynx }\end{array}$ & $\$ 535(0.17 \%)$ & $\$ 5,535(0.10 \%)$ & $\$ 544(0.08 \%)$ & $\$ 6,613(0.10 \%)$ \\
\hline Thyroid & $\$ 14(0.004 \%)$ & $\$ 474(0.01 \%)$ & $\$ 71(0.01 \%)$ & $\$ 559$ (0.01\%) \\
\hline Total & $\$ 930$ (0.29\%) & $\$ 14,128(0.26 \%)$ & $\$ 1,857(0.26 \%)$ & $\$ 16,915(0.26 \%)$ \\
\hline
\end{tabular}

a: Baseline VSL assumptions assume an income-elasticity of 1.5; please see methods and appendix for details. 


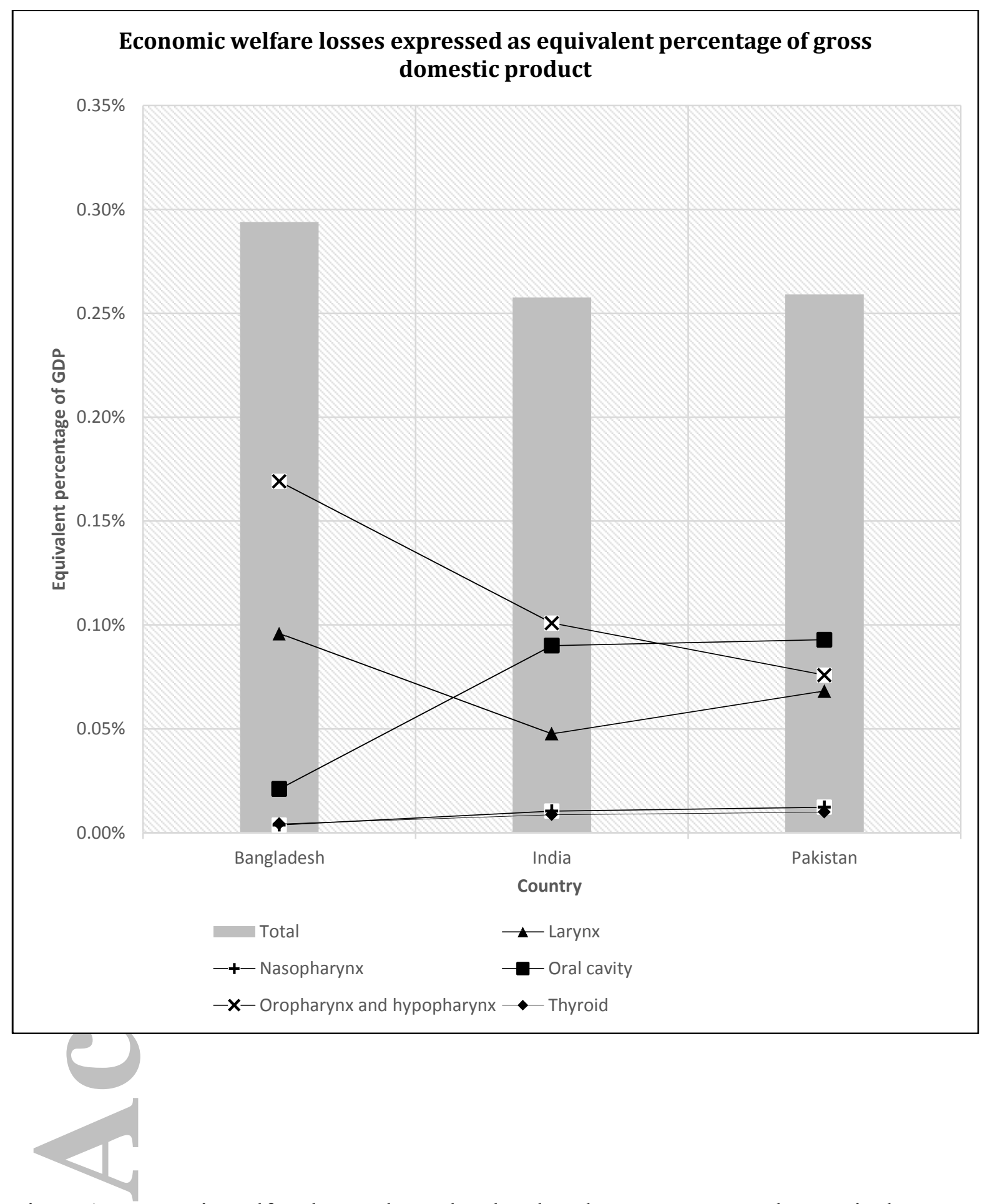

Figure 1: Economic welfare losses due to head and neck cancer expressed as equivalent percentage of GDP by country and site of origin. Baseline value of a statistical life assumptions are applied; please see methods and appendix for details.

John Wiley \& Sons, Inc.

This article is protected by copyright. All rights reserved. 


\section{References}

1. United Nations. The Millenium Development Goals Report 2014. New York, New York: United Nations; 2014.

2. Goss PE, Strasser-Weippl K, Lee-Bychkovsky BL, et al. Challenges to effective cancer control in China, India, and Russia. Lancet Oncol 2014;15:489-538.

3. Knaul FM, Atun R, Farmer P, Frenk J. Seizing the opportunity to close the cancer divide. Lancet 2013;381:2238-9.

4. Meara JG, Leather AJ, Hagander L, et al. Global Surgery 2030: Evidence and solutions for achieving health, welfare, and economic development. Surgery 2015.

5. Bickler SW, Weiser TG, Kassebaum N, et al. Global burden of surgical conditions. Disease Control Priorities 3rd Edition: Economic Evaluation for Health: World Bank; 2014.

6. Alkire BC, Raykar NP, Shrime MG, et al. Global access to surgical care: a modelling study. Lancet Glob Health 2015;3:e316-23.

7. Institute of Medicine (U.S.). Committee on Cancer Control in Low- and Middle-Income Countries., Sloan FA, Gelband H. Cancer control opportunities in low- and middle-income countries. Washington, DC: National Academies Press; 2007.

8. Torre LA, Bray F, Siegel RL, Ferlay J, Lortet-Tieulent J, Jemal A. Global cancer statistics, 2012. CA Cancer J Clin 2015;65:87-108.

9. GLOBOCAN 2012 v1.0, Cancer Incidence and Mortality Worldwide: IARC CancerBase No. 11. International Agency for Research on Cancer, 2014. (Accessed October 17, 2014, at http://globocan.iarc.fr.)

10. The World Bank: open data (world development indicators). 2014. (Accessed October 15th, 2014, at http://data.worldbank.org/.)

11. Lozano R, Naghavi M, Foreman K, et al. Global and regional mortality from 235 causes of death for 20 age groups in 1990 and 2010: a systematic analysis for the Global Burden of Disease Study 2010. Lancet 2012;380:2095-128.

John Wiley \& Sons, Inc.

This article is protected by copyright. All rights reserved. 
12. Chao TE, Sharma K, Mandigo M, et al. Cost-effectiveness of surgery and its policy implications for global health: a systematic review and analysis. Lancet Glob Health 2014;2:e334-45.

13. Sullivan R, Alatise OI, Anderson BO, et al. Global cancer surgery: delivering safe, affordable, and timely cancer surgery. Lancet Oncol 2015;16:1193-224.

14. Jamison DT, Summers LH, Alleyne G, et al. Global health 2035: a world converging within a generation. Lancet 2013;382:1898-955.

15. WHO. Macroeconomics and health: investing in health for economic development. Geneva: WHO; 2001.

16. Murray CJ, Ezzati M, Flaxman AD, et al. GBD 2010: design, definitions, and metrics. Lancet 2012;380:2063-6.

17. Schelling TC, Bailey MJ, Fromm G. The life you save may be your own. Problems in public expenditure analysis : papers presented at a conference of experts held September 15 - 16, 1966 ; [this was the second Brookings conference on government expenditures] 1968:127-62.

18. Viscusi WK, Aldy JE. The value of a statistical Life: a critical review of market estimates throughout the world. Journal of Risk Uncertainty 2003;27:5-76.

19. Guidance on the Treatment of the Economic Value of Statistical Life. 2013. (Accessed November 12, 2013, 2013, at http://www.dot.gov/sites/dot.gov/files/docs/VSL\%20Guidance_2013.pdf.)

20. Hammitt JK, Robinson LA. The income elasticity of the value per statistical life: transferring estimates between high and low income populations. Journal of Benefit-Cost Analysis 2011;2:Article 1.

21. John R, Ross H. The global economic cost of cancer: a report summary: American Cancer Society; 2010.

22. Bloom DE, Cafiero ET, Jané-Llopis E, et al. The global economic burden of noncommunicable diseases. Geneva: World Economic Forum; 2011.

23. Jamison DT, Jha P, Laxminarayan R, Ord T. Infectious disease, injury, and reproductive Health. Copenhagan Consensus 2012. Copenhagan: Copenhagen Consensus Center; 2012.

John Wiley \& Sons, Inc. 
24. Alkire BC, Shrime MG, Dare AJ, Vincent JR, Meara JG. Global economic consequences of selected surgical diseases: a modelling study. Lancet Glob Health 2015;3 Suppl 2:S21-7.

25. Murray CJ, Vos T, Lozano R, et al. Disability-adjusted life years (DALYs) for 291 diseases and injuries in 21 regions, 1990-2010: a systematic analysis for the Global Burden of Disease Study 2010. Lancet 2012;380:2197-223.

26. Pramesh CS, Badwe RA, Borthakur BB, et al. Delivery of affordable and equitable cancer care in India. Lancet Oncol 2014;15:e223-33.

27. Mahal A, Karan A, Fan VY, Engelgau M. The economic burden of cancers on Indian households. PLoS One 2013;8:e71853.

28. Sankaranarayanan R, Swaminathan R, Brenner H, et al. Cancer survival in Africa, Asia, and Central America: a population-based study. Lancet Oncol 2010;11:165-73.

29. Mallath MK, Taylor DG, Badwe RA, et al. The growing burden of cancer in India: epidemiology and social context. Lancet Oncol 2014;15:e205-12.

30. Khan Z. An Overview of Oral Cancer in Indian Subcontinent and Recommendations to Decrease its Incidence. WebmedCentral Cancer 2012;3.

31. Marur S, D'Souza G, Westra WH, Forastiere AA. HPV-associated head and neck cancer: a virusrelated cancer epidemic. Lancet Oncol 2010;11:781-9.

32. Bahl A, Kumar P, Dar L, et al. Prevalence and trends of human papillomavirus in oropharyngeal cancer in a predominantly north Indian population. Head Neck 2014;36:505-10.

33. Sankaranarayanan R, Ramadas K, Thomas G, et al. Effect of screening on oral cancer mortality in Kerala, India: a cluster-randomised controlled trial. Lancet 2005;365:1927-33.

34. Sankaranarayanan R. Health care auxiliaries in the detection and prevention of oral cancer. Oral Oncol 1997;33:149-54.

35. Kulkarni MR. Head and Neck Cancer Burden in India. Int J Head and Neck Surg 2013;4:29-35.

36. Trivedi NP, Trivedi P, Trivedi H, Trivedi S, Trivedi N. Optimizing multimodality treatment for head and neck cancer in rural India. Indian J Cancer 2012;49:225-9.

John Wiley \& Sons, Inc.

This article is protected by copyright. All rights reserved. 
37. Holmer H, Lantz A, Kunjumen T, et al. Global distribution of surgeons, anaesthesiologists, and obstetricians. Lancet Glob Health 2015;3 Supp1 2:S9-11.

38. Meara JG, Leather AJ, Hagander L, et al. Global Surgery 2030: evidence and solutions for achieving health, welfare, and economic development. Lancet 2015.

39. Lipnick M, Mijumbi C, Dubowitz G, et al. Surgery and anesthesia capacity-building in resourcepoor settings: description of an ongoing academic partnership in Uganda. World J Surg 2013;37:488-97. 40. Ozgediz D, Kijjambu S, Galukande M, et al. Africa's neglected surgical workforce crisis. Lancet 2008;371:627-8.

41. Sullivan R, Badwe RA, Rath GK, et al. Cancer research in India: national priorities, global results. Lancet Oncol 2014; 15:e213-22.

42. Farmer P, Meara JG. Commentary: The agenda for academic excellence in "global" surgery. Surgery 2013;153:321-2.

43. National Research Council (U.S.). Committee on Preventing the Global Epidemic of Cardiovascular Disease: Meeting the Challenges in Developing Countries., Fuster V, Kelly BB, Institute of Medicine (U.S.). Committee on Preventing the Global Epidemic of Cardiovascular Disease: Meeting the Challenges in Developing Countries. Promoting cardiovascular health in the developing world : a critical challenge to achieve global health. Washington, D.C.: National Academies Press; 2010.

44. Forman D, de Martel C, Lacey CJ, et al. Global burden of human papillomavirus and related diseases. Vaccine 2012;30 Suppl 5:F12-23.

45. Madheswaran S. Measuring the value of statistical life: estimating compensating wage differentials among workers in India. Social Indicators Research 2007;84:83-96.

46. Anand S, Hanson K. Disability-adjusted life years: a critical review. J Health Econ 1997;16:685702.

47. Chisholm D, Stanciole AE, Tan Torres Edejer T, Evans DB. Economic impact of disease and injury: counting what matters. BMJ 2010;340:c924.

John Wiley \& Sons, Inc. 

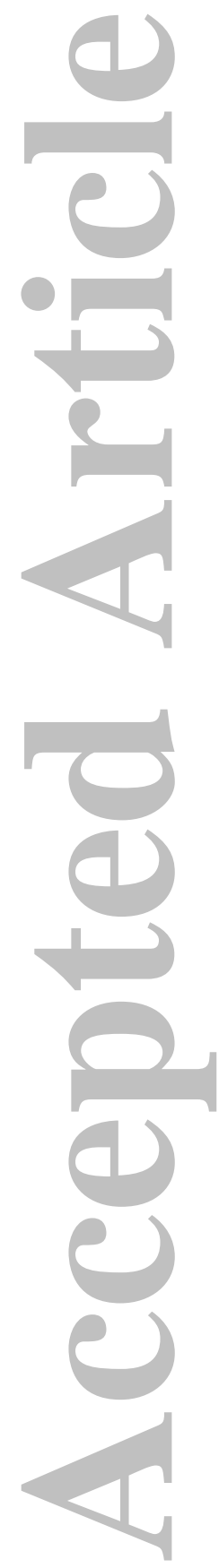

John Wiley \& Sons, Inc.

This article is protected by copyright. All rights reserved. 


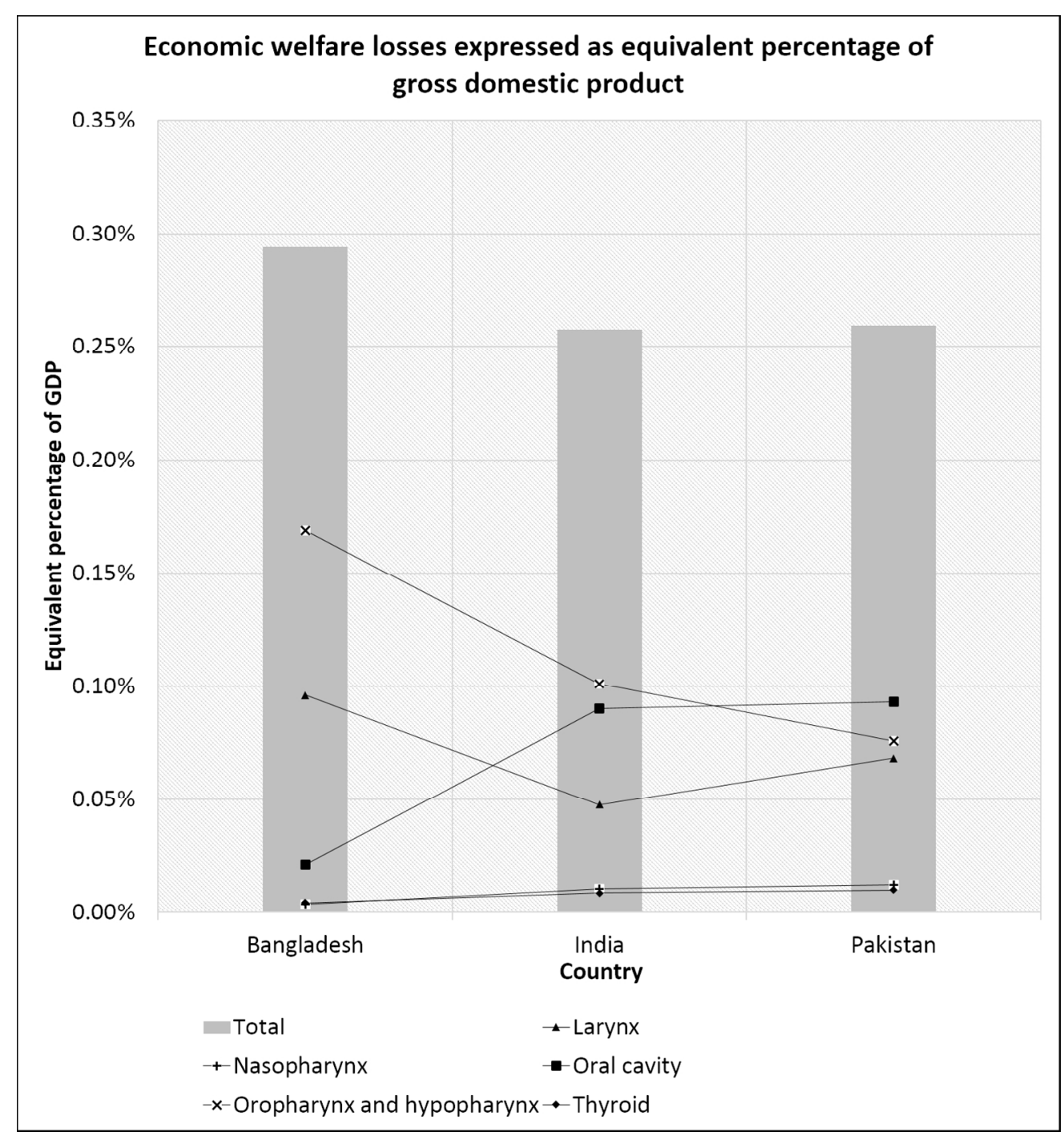

Figure 1 Legend: Economic welfare losses due to head and neck cancer expressed as equivalent percentage of GDP by country and site of origin. Baseline value of a statistical life assumptions are applied; please see methods and appendix for details.

$262 \times 281 \mathrm{~mm}(150 \times 150 \mathrm{DPI})$

John Wiley \& Sons, Inc.

This article is protected by copyright. All rights reserved. 


\section{Tables}

Table 1: Total deaths by country and cancer site of origin using Institute for Health Metrics and Evaluation estimates

\begin{tabular}{|c|c|c|c|c|}
\hline \multicolumn{4}{|c|}{ Country } & \multirow[b]{2}{*}{ Total } \\
\hline Site of Origin & Bangladesh & India & Pakistan & \\
\hline Larynx & 6512 & 20267 & 4106 & 30885 \\
\hline Nasopharynx & 260 & 3791 & 630 & 4681 \\
\hline Oral cavity & 1534 & 32063 & 4797 & 38393 \\
\hline $\begin{array}{l}\text { Oropharynx and } \\
\text { Hypopharynx }\end{array}$ & 11478 & 38942 & 4353 & 54772 \\
\hline Thyroid & 328 & 3742 & 591 & 4661 \\
\hline Total & 20112 & 98804 & 14477 & 133392 \\
\hline
\end{tabular}

Table 2: Economic welfare losses (millions, 2010 USD, PPP) by country and cancer site of origin using baseline value of a statistical life (VSL) assumptions ${ }^{\text {a }}$ (equivalent percentage of gross domestic product)

\begin{tabular}{|c|c|c|c|c|}
\hline & & Country & & \\
\hline Site of Origin & Bangladesh & India & Pakistan & Total \\
\hline Larynx & $\$ 303(0.10 \%)$ & $\$ 2,610(0.05 \%)$ & $\$ 489(0.07 \%)$ & $\$ 3,403(0.05 \%)$ \\
\hline Nasopharynx & $\$ 12(0.004 \%)$ & $\$ 571(0.01 \%)$ & $\$ 88(0.01 \%)$ & $\$ 670$ (0.01\%) \\
\hline Oral cavity & $\$ 67(0.02 \%)$ & $\$ 4,938(0.09 \%)$ & $\$ 666$ (0.09\%) & $\$ 5,670(0.09 \%)$ \\
\hline $\begin{array}{r}\text { Oropharynx and } \\
\text { Hypopharynx }\end{array}$ & $\$ 535$ (0.17\%) & $\$ 5,535$ (0.10\%) & $\$ 544(0.08 \%)$ & $\$ 6,613(0.10 \%)$ \\
\hline Thyroid & $\$ 14(0.004 \%)$ & $\$ 474(0.01 \%)$ & $\$ 71(0.01 \%)$ & $\$ 559(0.01 \%)$ \\
\hline Total & $\$ 930$ (0.29\%) & $\$ 14,128(0.26 \%)$ & $\$ 1,857(0.26 \%)$ & $\$ 16,915(0.26 \%)$ \\
\hline
\end{tabular}

a: Baseline VSL assumptions assume an income-elasticity of 1.5; please see methods and appendix for details. 


\section{Web Appendix}

The Disability-Adjusted Life Year

The manner in which disability adjusted life-years (DALYs) are calculated has evolved over the course of updates to the Global Burden of Disease Study, ${ }^{1}$ and we will only consider the most recent methodology. The basic formula for calculating the number of DALYs in a population secondary to a disease is:

(1)

$$
\begin{aligned}
& D A L Y S=Y L D+Y L L, \\
& Y L D=P \cdot D W \\
& Y L L=N \cdot L E
\end{aligned}
$$

where $Y L D=$ years lost due to disability, $Y L L=$ years of life lost, $N=$ total number of deaths due to disease in reference year, $L E=$ life expectancy at age of death, $P=$ prevalence, and $D W=$ disability weight (ranges from $0-1$, with $0=$ complete health, $1=$ death). In the most recent global burden of disease study, disability weights are obtained by asking groups of lay people to consider two health states and determine which state represents better health. ${ }^{2}$ Using an iterative process by which these health states are statistically ranked, a disability weight is calculated where complete health is rated as 0 , and death is rated as 1 .

\section{Discounting}

In previous global burden of disease studies, the DALY has incorporated various assumptions regarding time and age-preferences for calculating DALYs. Although the most recent update has abandoned these assumptions, they remain crucial when DALYs are used to assess future economic consequences and are therefore discussed in this publication. 
Discounting is a common practice in economic analyses and is used to determine the present value of cash flows that will be realized in the future. As we wish to convert future YLLs to economic burden in present value terms, we utilize discounting in our DALY calculations.

The inclusion of discounting results in the following years of life lost (YLL) formula:

$$
Y L L_{a, i, d, t}=\int_{a}^{L E_{a, i, t}} e^{-r(x-a)} d x
$$

where $a=$ age of death, $L E=$ life-expectancy, $x=$ age integrated over years of life lost (YLLs), $r$ $=$ discount rate $(3 \%$ in this study), $a=$ age, $L E=$ life expectancy, $d=$ disease, $i=$ country, and $t=$ year. ${ }^{3}$ Years lost to disability (YLDs) can be calculated using an incidence or prevalence perspective. The former would allow for discounting, while the latter does not. The global burden of disease study provides prevalence YLDs, therefore:

$$
Y L D_{a, d, i, t}=P_{a, d, i, t} \cdot D W_{d}
$$

Although we previously relied on a modification of the age-weighting formula included in the original DALY, ${ }^{4}$ it is not consistent with economic theory and we have therefore abandoned the use of this function.

The perspective from which DALYs are calculated can result in different outcomes with the same inputs. A complete discussion of different approaches can be found elsewhere, ${ }^{5}$ but it is important to clarify which DALYs are used as a basis for this study to understand the meaning of the implied economic burden. Consistent with the current global burden of disease approach, YLLs are calculated from an incidence perspective, such that all deaths from a disease in one year are multiplied by life-expectancy. YLLs, then, account for future years of lost life and apply them to the reference year. YLDs, however, are calculated from a prevalence perspective; only 
the morbidity incurred during the reference year is taken into account. The combination of these variations of YLLs and YLDs implies that the burden of disease is made up of the present value of future years lost due to the premature mortality that year plus the morbidity incurred during the reference year.

\section{Converting DALYs averted to Economic Benefit}

Empirical evidence suggests VSL varies with age. ${ }^{6}$ To value DALYs using the value of a statistical lifeyear (VSLY) approach, we first estimated the peak value of a statistical life year $\left(\mathrm{VSL}_{\mathrm{p}}\right)$ in each country, $i$, using the following formula: ${ }^{7}$

$$
V S L_{p, i}=V S L_{p, U S A} \cdot\left[\frac{Y C_{i}}{Y C_{U S A}}\right]^{I E-V S L}
$$

where $V S L_{p}=$ the peak value of a statistical life, $Y C=$ GDP per capita in 2010, and $I E-V S L=$ the income elasticity of VSL. We used GDP per capita estimates based on the purchasing power parity (PPP) approach. ${ }^{7}$ One can then calculate the VSLY by treating VSL as the present value of an annuity, where the VSLY is the payment over the remaining discounted years of life. ${ }^{8}$

Empirical evidence indicates that VSL and VSLY are not constant over an individual's lifetime, nor do they monotonically decrease with age as intuition might suggest. Instead, both VSL and VSLY follow an inverted $\mathrm{U}$ shape - initially rising with age before falling. ${ }^{6}$ We incorporate this concept into our model, along with assumptions regarding income, time-preferences for money, and country and agespecific life-expectancy. Therefore, we must calculate age-specific VSLs in each country analyzed. An age-specific VSL $\left(\mathrm{VSL}_{\mathrm{a}}\right)$ can be estimated with the following:

$$
V S L_{a, i}=V S L_{p, i} \cdot f(a)_{i}
$$

where $a$ represents age, and $f(a)$ is a quartic function that adjusts a country's peak VSL to $\mathrm{VSL}_{\mathrm{a}}$ based on the proportion of life lived. To estimate $\mathrm{f}(\mathrm{a})$, we fit five data points where the explanatory variable is 
proportion of life lived, and the dependent variable is represented by $\mathrm{VSL}_{\mathrm{a}} / \mathrm{VSL}_{\mathrm{p}}$, (or the proportion one would have to multiply $\mathrm{VSL}_{\mathrm{p}}$ by to derive the age specific VSL). We based our points on Aldy and Viscusi’s 2008 study, “Adjusting the Value of a Statistical Life for Age and Cohort Effects." ${ }^{\text {T }}$ There is uncertainty regarding the VSL for children; however there is general consensus that the VSL of a child is at least that of an adult. ${ }^{9}$ To account for this, we set a child's VSL as equal to the first data point in the Aldy and Viscusi study, or roughly 1/4 of life expectancy. It is important to note that formal estimates of VSL have been performed in India, ${ }^{10}$ with a minimum VSL estimate of $\$ 1.2$ million in 2000 U.S. dollars. ${ }^{7}$ When this value is updated to 2010 dollars, the estimate is roughly equivalent to setting IE-VSL $=0.55$.

Our upper estimates of VSL are therefore compatible with the available literature.

As discussed above, the total welfare losses $(V L W)$ of a disease are given by:
(8)
$V L W_{d}=V S L Y \cdot D A L Y S_{d}$

Given that we are interested in accounting for age in our model, we must define an age-specific VSLY, or $\operatorname{VSL} Y_{a}$, that would then be used to value DALYs that are incurred at a given age.

The following reveals how to calculate $\operatorname{VSL} Y_{a}$.

Begin by substituting equation (1) into equation (8):

$$
V L W_{a, d, i, t}=V S L Y_{a, i, t}\left(Y L L_{a, d, i, t}+Y L D_{a, d, i, t}\right)
$$

To define an age-specific economic burden, substitute equation (4) for YLLs into equation (9).

$$
V L W_{a, i, t}=V S L Y_{a, i, t}\left[Y L D_{a, i, t}+\int_{a}^{L E_{a, i, t}} e^{-r(x-a)} d x\right]
$$

where $V L W_{a}=$ the age-specific total economic welfare losses, $V S L Y_{a}=$ the age-specific value of a statistical life-year, $a=$ age of death, $L E=$ age and country-specific life-expectancy, and $Y L D_{a}=$ agespecific YLDs given by the global burden of disease study. 
Assume that a disease causes death at age $a$ in an individual; in this case, YLDs are now equal to 0, and the value of lost welfare in equation (10) is equal to $\mathrm{VSL}_{\mathrm{a}}$ (or VSL at age a).

$$
V S L_{a, i, t}=V S L Y_{a, i, t} \int_{a}^{L E_{a, i, t}} e^{-r(x-a)} d x
$$

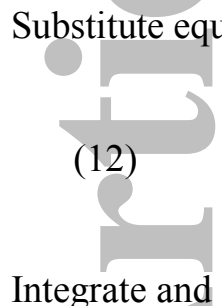

ion (7) into (11):

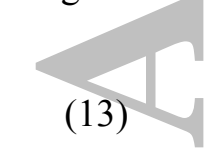

$$
V S L_{p, i, t} \cdot f(a)_{i}=V S L Y_{a . i, t} \int_{a}^{L E_{a, i, t}} e^{-r(x-a)} d x
$$

This is the formula we use to estimate $\operatorname{VSL} Y_{a}$, which is then multiplied by age-specific DALYs.

John Wiley \& Sons, Inc. 
Table 1 (Sensitivity Analysis): Economic welfare losses (millions, 2010 USD, PPP) by disease with varying assumptions regarding how value of a statistical life changes with income (equivalent percentage of gross domestic product)

\begin{tabular}{|rcc}
\hline Site of Origin & IE-VSL * $^{-1.0}$ & IE-VSL $=\mathbf{0 . 5 5}$ \\
Larynx & $\$ 11,640(0.18 \%)$ & $\$ 35,697(0.55 \%)$ \\
Nasopharynx & $\$ 2,218(0.03 \%)$ & $\$ 6,531(0.10 \%)$ \\
Oral cavity & $\$ 18,696(0.29 \%)$ & $\$ 54,838(0.84 \%)$ \\
$\begin{array}{r}\text { Oropharynx and } \\
\text { Hypopharynx }\end{array}$ & $\$ 22,474(0.34 \%)$ & $\$ 68,456(1.05 \%)$ \\
Thyroid & $\$ 1,854(0.03 \%)$ & $\$ 5,481(0.08 \%)$ \\
Total & $\$ \mathbf{5 6 , 8 8 3 ( 0 . 8 7 \% )}$ & $\mathbf{\$ 1 7 1 , 0 0 3 ( 2 . 6 2 \% )}$ \\
\hline
\end{tabular}

*IE-VSL: Income elasticity of VSL

\section{References:}

.1. Murray CJ, Vos T, Lozano R, et al. Disability-adjusted life years (DALYs) for 291 diseases and injuries in 21 regions, 1990-2010: a systematic analysis for the Global Burden of Disease Study 2010. Lancet. Dec 15 2012;380(9859):2197-2223.

2. Salomon JA, Vos T, Hogan DR, et al. Common values in assessing health outcomes from disease and injury: disability weights measurement study for the Global Burden of Disease Study 2010. Lancet. Dec 15 2012;380(9859):2129-2143.

3. Lopez AD, Mathers CD, Ezzati M, Jamison DT, Murray CJL, Disease Control Priorities Project. Global burden of disease and risk factors. New York, NY; Washington, DC: Oxford University Press and World Bank; 2006.

4. Alkire BC, Vincent JR, Burns CT, Metzler IS, Farmer PE, Meara JG. Obstructed labor and caesarean delivery: the cost and benefit of surgical intervention. PLoS One. 2012;7(4):e34595.

5. Schroeder SA. Incidence, prevalence, and hybrid approaches to calculating disabilityadjusted life years. Popul Health Metr. 2012;10(1):19. 
6. Aldy JE, Viscusi WK. Adjusting the value of a statistical life for age and cohort effects. Rev. Econ. Stat. 2008;90(3):573-581.

7. Viscusi WK, Aldy JE. The value of a statistical Life: a critical review of market estimates throughout the world. Journal of Risk Uncertainty. 2003;27(1):5-76.

8. Hammitt JK. Valuing changes in mortality risk: lives saved versus life years saved.

Review of Environmental Economics and Policy. 2007;1(2):228-240.

9. Roman HA, Hammitt JK, Walsh TL, Stieb DM. Expert elicitation of the value per statistical life in an air pollution context. Risk Anal. Dec 2012;32(12):2133-2151.

10. Shanmugam K. The Value of Life: Estimates from Indian Labour Market. Indian Econ. J. 1996;44(4):105-114.

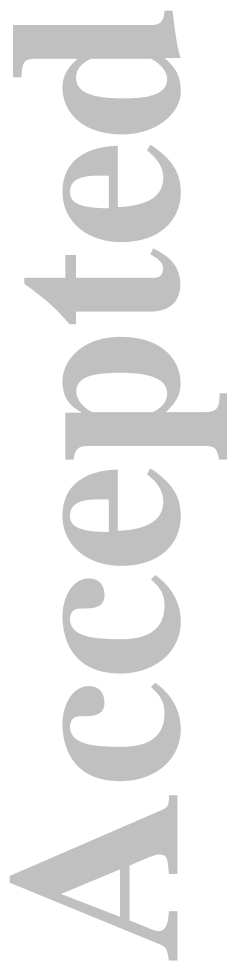

John Wiley \& Sons, Inc. 


\section{University Library}

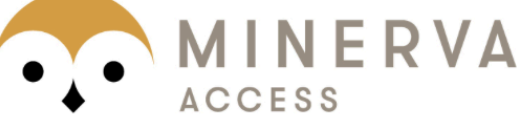

A gateway to Melbourne's research publications

Minerva Access is the Institutional Repository of The University of Melbourne

Author/s:

Alkire, BC;Bergmark, RW;Chambers, K;Lin, DT;Deschler, DG;Cheney, ML;Meara, JG

Title:

Head and neck cancer in South Asia: Macroeconomic consequences and the role of the head and neck surgeon

Date:

2016-08-01

Citation:

Alkire, B. C., Bergmark, R. W., Chambers, K., Lin, D. T., Deschler, D. G., Cheney, M. L. \& Meara, J. G. (2016). Head and neck cancer in South Asia: Macroeconomic consequences and the role of the head and neck surgeon. HEAD AND NECK-JOURNAL FOR THE SCIENCES AND SPECIALTIES OF THE HEAD AND NECK, 38 (8), pp.1242-1247. https:// doi.org/10.1002/hed.24430.

Persistent Link:

http://hdl.handle.net/11343/291112 